\title{
Gender-Based Violence and Adherence to Anti-Retroviral Therapy among Hiv-Infected Women Attending Care and Treatment Clinic, Mbeya Region 2017
}

\author{
Luoga, Alex Robert ${ }^{1,2^{*}}$, J. Harris ${ }^{3}$, J. Gibson ${ }^{2,3}$, G. Kwesigabo ${ }^{1}$ \\ ${ }^{1}$ Muhimbili University of Health and Allied Science (MUHAS) \\ ${ }^{2}$ Tanzania Field of Epidemiology and Laboratory Training Program (TFELTP) \\ ${ }^{3}$ Centers for Disease Control and prevention Tanzania
}

\begin{abstract}
*Corresponding Author: Luoga, Alex Robert, Muhimbili University of Health and Allied Science (MUHAS), Tanzania. Email: luogalex@yahoo.com
\end{abstract}

\begin{abstract}
Background: About $62 \%$ of women living with HIV receive antiretroviral therapy (ART) in Tanzania. To gain the clinical benefits of ART strict adherence is necessary. However, sustaining high levels of adherence to ART is a challenge. Given this importance, simple and accurate measures of adherence are essential, and identifying barriers to achieving high adherence levels is a key, the prevalence of gender based violence in Tanzania is high, but there is limited information about its association with adherence to ART.

Objective: This study aimed at determining the relationship between Gender Based Violence and ART adherence among women on ART attending CTC in Mbeya Region.

Methodology: Analytical cross-sectional study was conducted among HIV-infected women aged above $18 y e a r s$ on ART attending CTC in Mbeya Regional hospital. A probability sampling was drawn and interviewed after informed consent using structured questionnaire. Collected data was analyzed using Epi Info version 7

Results: A total of 411 participants recruited into this study, majority their age ranged from 28-38years, $45.5 \%$ were married,30\% widowed,58.9\% completed primary education, and 78\% were self employed. $61(14.8 \%)$ had reported poor adherent to their ART treatment while prevalence of ever having violence were (24.8\%).

Factors that were independently associated with poor ART adherence were; disclosure status $(O R=2.84$, 95\%CI:1.56-5.14), physical violence $(O R=2.22,95 \% C I: 1.4 .7)$, psychological violence $(O R=5,95 C I: 2.38-7.61)$, alcohol use $(O R=2.28,95 \%$ CI:1.31-3.97), participants from rural areas $(O R=1.91,95 \%$ CI:1.09-3.33), felling difficult to take medication (OR=3.46, 95\%CI: 1.89-6.33), and stigma(OR=2.4,95CI:1.37-4.2), while socio demographic factors were not associated with poor ART adherence

Conclusion: Exposure to violence may signify poor adherence to ART for women. Therefore routine screening of women for exposure to violence may be useful in clinical settings where HIV services are provided in order to increase adherence to ART.

Keywords: ART, Adherence, HIV/AIDS, Gender based violence, Disclosure status.

Abbreviations: AIDS: Acquired immune deficiency syndrome; ART: Antiretroviral therapy; ARV: Anti retro viral; CD4: Cluster differentiation Cell tyepe4: $\boldsymbol{G B V}$; Gender based violence: HIV: Human immune deficiency virus; CTC: Care and treatment center; IPV: Intimate partner violence: MoHCGEC: Ministry of Health, Community Development, Gender, Elderly and Children: MUHAS; Muhimbili University of Health and allied Science: PLWH: People living with HIV; PMTCT: Prevention of Mother to Child Transmission of HIV: UNAIDS: Joint United Nations Programme on HIV/AIDS; WHO: World health organization.
\end{abstract}

\section{INTRODUCTION}

In Tanzania, Human Immunodeficiency Virus (HIV) and Acquired Immunodeficiency Syndrome (AIDS) remain a considerable problem with an adult HIV prevalence of $5.1 \%(4)$. Due to the high prevalence of infection, the Tanzanian Government began disseminating free antiretroviral therapy (ART) in 2004. The aim was to provide ART for as many HIVinfected patients as possible (1).ART slows disease progression and decreases morbidity and mortality. Achieving $>95 \%$ adherence to the drug regimen promotes a good virological response and prevents the emergence of viral resistance(5) $(6,7)$. 
Globally, many factors have been associated with poor adherence, including medication side effects, low socio-economic status, healthcare system challenges, such as coverage issues, patient challenges related to age, knowledge, psychosocial issues, psychiatric illness, substance abuse, and lack of social support $(8,9)$. Studies have identified a range of barriers to treatment adherence at different levels, including disclosing HIV status to partners, stigma and discrimination, lack of support, poverty, nutrition (lack of food), self-assessed lack of need for further treatment, perceptions of HIV and treatment, disruption in schedules, and programlevel factors(1).

Factors affecting HIV-infected women's ability to access antiretroviral include Gender based violence(GBV), financial and time costs of traveling to service points, and the need to seek permission from partners to access services(10). From Demographic and Health Survey(DHS) in 2012 data from eight countries in Africa, 20 to $50 \%$ of married women experienced GBV(11). GBV may also interfere with the ability to maintain adherence to ARV treatment $(1,10)$. Fears of experiencing violence may potentially delay a person's decision to disclose her HIV status and seek treatment when necessary(12), which in turn has a significant impact on treatment adherence: when women are fearful of violence from their partners, they may be more likely to default on medications $(13,14)$.

Violence against women is a common practice in Tanzania(15).The Tanzania Demographic Health Survey 2010 revealed that nearly half $(45 \%)$ of Tanzanian women aged 15-49 years have experienced physical or sexual violence. The survey revealed regional prevalence variations of gender based violence, Mara (72\%), Dodoma (71\%), Unguja (7\%) and Pemba (5\%) had lower levels(16). More over $56 \%$ of ever-partnered women in Mbeya and 41\% in Dar es Salaam had ever experienced physical or sexual violence at the hands of a partner, in urban district of Moshi $21 \%$ of women reported having experienced GBV(17).

\subsection{Statement of the Problem}

Globally, poor adherence to ART has gained great attention. Adherence rates of $>95 \%$ are needed to maximize the benefits of ART, achieving such high rates over a long period of time is a challenge. In Tanzania Studies indicate that adherence to ART among PLWHA is consistently less than $80 \%(18,19)$.Women are significantly more likely than men to be victims of poor ART adherence due to GBV, which has been considered to be a driver of the epidemic among women in sub-Saharan Africa. As mentioned above, GBV is widespread in subSaharan African countries (20)

Poor adherence to ARVs may result in treatment failure and the emergence of drug resistant strains of HIV and require a change of treatment regimens, thereby greatly increasing treatment costs. Moreover, non-adherence to treatment has an impact on livelihood and development of the community and nation in general. Despite health risks associated with GBV among HIV infected women, GBV remains an understudied factor in the literature around HIV care and treatment.

This study aims to examine the relationship between Gender Based Violence and ART adherence among women on ART attending care and treatment in Mbeya referral hospital, Tanzania.

\subsection{Rationale of the Study}

Poor adherence to ART among women infected with HIV is a problem. Gender based violence has shown to recently increase in prevalence in the world (17) with Africa being the most affected by gender based violence. However as few studies have investigated the relationship between GBV and ART adherence, little is as known about this relationship in Tanzania. Attention is required for the full understanding of the contribution of GBV to non-adherence to ART. This study aimed at further investigating the relationship between poor ART adherence and GBV to support interventions and increase access to and success of ARVs.

\section{Literature REVIEW}

\subsection{Poor ART Adherence among PLWHA}

The challenges of adherence to ART identified include factors related to patients and their families, socioeconomic factors, medication, and healthcare systems, low adherence to treatment has been associated with higher hospitalization rates, productivity loss, disease progression, and death in both high-income and resource-limited settings(21)(19)

A study was done by Nsimba S. On Barriers to ARV Adherence among HIV / AIDS Positive Persons taking Anti-Retroviral Therapy in Tanzania shows factors mentioned to constrain adherence include; stigma, poor social support, wrong beliefs on HIV causation, lack of food, 
side-effects, inadequate counseling, long waiting time, costs related to transport and long distance to the facility (23).

A study done by Sasaki Y. on Adherence to antiretroviral therapy in rural Zambia, full adherence was associated with being female, having a spouse who were also on ART. Reasons for missed doses were long distance to health facilities, food insufficiency, and being busy with other activities was associated with poor ART adherence. However, other studies have also shown that HIV-positive females often experience gender-related barriers to accessing health services, thus affecting ART adherence (24)(25).

Also in study conducted in Northern Ethiopia on level of adherence and predictors of adherence to the Option B + PMTCT revealed that mothers who were counseled on the correct intake of ARV medications were more likely to adhere to Option B+ PMTCT care than those who were not counseled (26). Previous studies demonstrated that sickness and economic instability as well as stock- out of ART as one of the factors associated with non-adherence to ART(27).

A study done by Hansana V. about Adherence to Antiretroviral Therapy in India (ART) among People Living with HIV the results revealed a statistically significant association with nonadherence in the 36 to 45 age group compared to those who were $\leq 35$ years or who were more than 46 years old as well being a graduate of a secondary school was also observed to have a statistically significant association with nonadherence. Patients who had been diagnosed HIV infected for more than 60 months reported statistically significantly better adherence than those who became aware of their HIV infection in the 36 to 45 months prior to the survey. Use of illegal drug substances was found to be statistically significantly associated with nonadherence $(23,24)$.

Study done by Victoria N. about HAART adherent among HIV infected patients in Nigeria, the study further reveled that poor adherence to medication was contributed by side effect , forgetting, poor availability of HAART and adverse effects to medication among (30).

Study done by Hampanda K. on IPV and HIVinfected women's non-adherence to ART in Lusaka, Zambia among women during pregnancy the study revealed experiencing IPV was associated with decreased odds of adherence to PMTCT during and after pregnancy. Physical violence had a less pronounced effect on nonadherence than emotional and sexual violence. (31)

\subsection{Types of GBV Experienced by Female Patients}

In a study done by S. Shamus, et al. on IPV after Disclosure of HIV among Pregnant Women in Harare, Zimbabwe, over $93 \%$ of women disclosed the HIV results to their partners. Factors associated with IPV were gender inequity, past IPV, risky sexual behaviors and living with relatives(32)

Durevall and Lindskog analyzed Demographic and Health Survey (DHS) data from eight countries, namely Malawi, Zambia, Zimbabwe, Kenya, Rwanda, Burkinafaso, Mali, and Liberia, and found that $20-50 \%$ of married women experienced IPV. Similarly, research conducted in Tanzania has documented unacceptably high levels of physical and sexual violence against women(11,12), also amulticountry study sponsored by WHO reported that $56 \%$ of everpartnered women in Mbeya and $41 \%$ in Dar es Salaam had ever experienced physical or sexual violence by their partner(17).

\subsection{Relationship Between Experiencing GBV and ART Adherence}

A study done in Tanzania on assessing the relationship between experiencing IPV and the occurrence of HIV infection found that violence was significantly higher among HIV-positive women than among HIV-negative women(12). Another study was done in India aiming to assess the relationship between experiencing IPV and the occurrence of HIV infection found that onethird of married Indian women reported experiencing physical IPV with or without sexual violence from their husbands; $7.7 \%$ reported both physical and sexual IPV, and $27.8 \%$ reported experiencing physical IPV in the absence of sexual violence.

A study done by Hatcher about Intimate partner violence and engagement in HIV care and treatment among women in England result from meta-analysis studies showed IPV to be significantly associated with lower ART use. IPV was associated with poorer self-reported ART adherence in seven studies and lower odds of viral load suppression in seven studies(13).

A study was done by Nicodimos S. about association between Domestic violence and 
Adherence to Antiretroviral Therapy in Southern India, lifetime experience of any type of violence was reported by participants. The most common type of violence reported was psychological violence, followed by physical violence. Sexual violence was the least frequently reported. Women who experienced violence were less likely to report $\geq 95 \%$ adherence to their ART medications whereas men who experienced violence were more likely to have $\geq 95 \%$ adherence(8). IPV remained significantly associated with non-adherence to all women who experienced IPV compared to women who did not experience any IPV (31).

A study done by (Nicodimos 2013) in India on association between domestic violence and adherence to ART among CTC attendees the results shows those who experienced violence reported $<95 \%$ adherence to ART than participants who did not experience violence (8).

\section{Methodology}

\section{Study Design}

Cross-sectional study design was conducted among HIV-infected women on ART who are attending CTC in Mbeya Regional referral hospital.

\section{Study Area}

The study was conducted in Mbeya region referral Hospital located in Mbeya city council. Mbeya region is among the regions of Tanzania with a high prevalence of HIV-infected persons located in the South-West of Tanzania. Mbeya Regional referral hospital is one the clinic currently serving for over 2,793 female clients on ART.

\section{Study Population}

The study population consisted of HIV-infected women on ART aged $\geq 18$ years during the time of study attending CTC at Mbeya regional Hospital

\section{Inclusion Criteria}

HIV-infected women attending CTC Mbeya Regional Hospital:

Aged 18 years \& above during time of study

$>$ Initiated on ART for at least six months

$>$ Who will be willing to participate in the study after the informed consent procedure

\section{Exclusion Criteria}

$>$ Women with mental disorders
$>$ Women not attending CTC clinic during time of study

\section{Sample Size Determination}

Since this study is descriptive, the formula for minimum sample estimation for descriptive studies will be used.

$$
\mathrm{n}=\frac{\mathrm{Z}^{2} \mathrm{P}(1-\mathrm{P})}{\mathrm{E}^{2}}
$$

Where; $\mathrm{n}=$ estimated sample size for infinite population

$\mathrm{P}=$ proportion of poor ART adherence $(19 \%$ by A.Muya, P.Geldsetzer, E.Hertzmark et al. on poor adherence to Antiretroviral Therapy among HIV-Infected Adults in Dar es Salaam, Tanzania)

$\mathrm{Z}=$ Critical value for the standard normal distribution for the $95 \%$ confidence interval around the mean. $=1.96$ (at. CI .95\%)

$E=$ Margin of error on estimate (set at 4\%)

After calculating and adding $10 \%$ for nonresponse the final sample size become 411

\section{Sampling Technique}

Systematic sampling method was adopted to select patients during the study period to obtain the desired sample size.

\section{Dependent Variables}

Poor ART adherence

\section{Independent Variables}

The independent variables were socio demographic factors and other factors such, area of residence, stigma, disclosure status, life time partner, economic status, employment status, GBV, distance from health facility, social support, and alcohol use.

\section{Data Collection Methods and Technique}

Structured closed ended questionnaire was prepared after review of relevant literatures. The data was collected through interview by using structured questionnaire from women attending ART clinic in Mbeya regional referral hospital. The data collection was carried out by three nurses on patients' appointment days.

\section{Training and Involvement of Research Assistants}

Three research assistants were trained for one day before actual data collection regarding the objectives of the study, population inclusion 
criteria, data collection techniques, interaction with the study interviewee, confidentiality, ethical guidelines, participants' rights, data collection tools, and data quality issues.

\section{Data Management and Analysis Plan}

Data were cross checked during data collection to ensure completeness and accuracy. Data were entered, cleaned for errors and analyzed using Epi info version 3.1.5. First the descriptive analysis was conducted and the result was displayed in the form of tables. Characteristics of individuals with $<95 \%$ ( with poor adherence) versus $\geq 95 \%$ adherence to ART and ever versus never experience of violence was compared using chi-squared tests for categorical variables and t-tests for continuous variables to assess statistical significance. logistic analysis was conducted to measure the association between the dependent variable and independent variables: patient factors (socio-demographic factors), medication and related characteristics (missed dose and medication side effects), system factors include access and health care providers' related characteristics and social support, stigma, and disclosure status were among community related factors using odds ratio and $95 \%$ confidence interval. Finally, Independent variables with $P$ value of $<=0.25$ at bivariate analysis were further advanced into multivariable logistic regression analysis in order to identify the factors associated with the adherence level. Statistical significance was set at $\mathrm{P}$-value $<0.05$

\section{Measures of Adherence}

Adherence was defined as taking drugs exactly as they are prescribed and it includes taking them at the right time and in the right doses(1), although there is no gold standard by which to measure adherence to medication.

Adherence measurement in this study based on patient recall of their compliance of the prescribed doses in over one month prior to the interview: This measure derived from the AIDS Clinical Trial Group (ACTG) assessment of adherence to antiretroviral medication and consistency of an inquiry about the number of missed doses over the past 30 days (Self reporting). This item was categorized into $\geq 95 \%$ (missing one or less doses) and $<95 \%$ adherence (missing more than one dose).

\section{Measures of Gender Based Violence}

The lifetime violence measure adopted from the World Studies of Abuse in Family Environment (World SAFE study) (8).
Participants were asked about their lifetime experience of violence. Participants who reported ever experiencing violence were asked about the types of violence to which they had been. Psychological violence defined as being "insulted, frightened, made afraid without touching, or abandoned "Physical violence defined as being "slapped, hit, kicked, or beaten", sexual violence defined as "ever being forced to have sex against the person's will". Participants who have experienced any form of above mentioned type of GBV were also evaluated for their association with ART adherence.

\section{Ethical Considerations}

Ethical clearance of conducting this research obtained from Muhimbili University of Health and Allied sciences (Ethical review board), permission of conducting this research in Mbeya Region obtained from Regional Medical Officer and Regional authorities DAS and RAS.

Further, for each study participant the objective of the study was stated by data collectors. In addition participants were informed that they have full right to refuse participating in the study and can interrupt the interview if not comfortable with it, but they were informed that their participation in the study is very important. Confidentiality of the information was assured and privacy of the study population was respected and kept as well.

\section{RESUltS}

\section{Demographic Characteristics of Study Population}

A total of 411 HIV positive women receiving ART were enrolled in the study, and the median age of responded was 39years, where 140 (34.1\%) was in age group 28-38 years. Most of study of participants187 (45.5\%) were married, 126(30.7\%) were widowed approximately more than half of them 242(58.9\%) had completed primary school, while $299(72.2 \%)$ were self employed. Nearly all of the participants (80.5\%) had disclosed their HIV status. More than half of the participants $287(69.8 \%)$ were from urban while 124(30.2\%) were from rural areas (Table1). 
Gender-Based Violence and Adherence to Anti-Retroviral Therapy among Hiv-Infected Women Attending Care and Treatment Clinic, Mbeya Region 2017

Table1. Socio demographic characteristics of women attending care and treatment clinic at Mbeya Regional Referral Hospital, 2017

\begin{tabular}{|c|c|c|c|}
\hline Characteristics & Category & Number & \% \\
\hline Age group & $18-28$ & 62 & 3.1 \\
& $28-38$ & 140 & 33.1 \\
& $38-48$ & 137 & 17.5 \\
\hline Marital status & $48+$ & 72 & 45.5 \\
& Married & 187 & 12.4 \\
& Single & 51 & 30.7 \\
& Widowed & 126 & 9.5 \\
& Separated & 39 & 1.9 \\
\hline Occupation & Divorced & 8 & 16.1 \\
& Employed in public sector & 66 & 11.2 \\
& Employed in private sector & 46 & 72.7 \\
\hline Education level & Self employed & 299 & 12.2 \\
& None & 50 & 58.9 \\
& Primary & 242 & 23.6 \\
& Secondary & 97 & 5.4 \\
\hline \multirow{2}{*}{ Residence } & Tertiary & 22 & 30.2 \\
\hline
\end{tabular}

Factors Associated with Poor Adherence to Anti Retrial Viral Therapy

In this study the overall adherence were $85.2 \%$, majority of respondents reported they had not missed more than single dose in the previous month. Of the 411 participants $103(25 \%)$ had measured viral load recently, $84(81.5 \%)$ had viral load <1000, and about 19(18.4\%) participants had viral load $>1000$ (Table: 2 ).

\section{Reasons for Missing Two or More ART Doses}

The most common reasons for missing two or more ART doses reported by study participants were being busy with activities $81.5 \%$, travelling $6.1 \%$, other reasons includes; fear $7.5 \%$ and being sick $4.8 \%$.

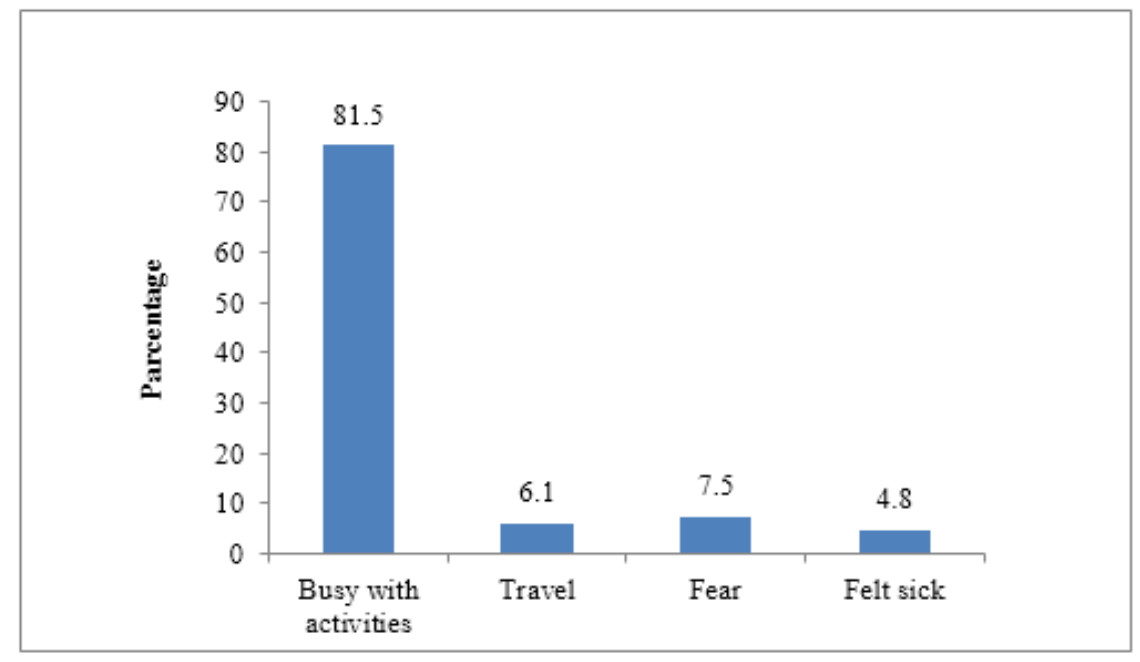

Figure1. Reasons for missing two or more ART doses

In bivariate analysis, none of the sociodemographic factors was found to be associated with poor adherent to ART. But somewhat women who were currently not married were likely to have poor ART adherence than married women but this association was not significant (OR=1.66, 95\% CI:0.64-2.93) (Table 2). Women with history of alcohol use were more likely to have poor ART adherence than those who did not take alcohol and were statistically significant
$(\mathrm{OR}=2.28, \quad 95 \% \mathrm{CI}: 1.31-3.97)$ Similarly, participants from rural areas $(\mathrm{OR}=1.91,95 \%$ CI:1.09-3.33), living $>10 \mathrm{~km}(\mathrm{OR}=1.67,95 \%$ CI:1-2.63), Perceived stigma (OR=2.4,95\% $\mathrm{CI}: 1.37-4.2)$. Moreover individuals who didn't disclosed their HIV status (OR=2.84,1.56-5.14), women who reported feeling difficult to take medication $(\mathrm{OR}=3.46,95 \% \mathrm{CI}: 1.89-6.33)$, while lifetime partner, having viral load >1000copies, having family support, being satisfied with health 
Gender-Based Violence and Adherence to Anti-Retroviral Therapy among Hiv-Infected Women Attending Care and Treatment Clinic, Mbeya Region 2017

care provider, not associated with poor adherence (Table3).

In multivariate analysis, the following were identified as risk factors for poor ART adherence. Psychological violence (OR=4.89, 95\%CI; 1.0722.2) (Table 5), women with history of alcohol use $(\mathrm{OR}=5.54,95 \% \mathrm{CI}$ (1.3-4.67), perceived self stigma $\quad(\mathrm{OR}=7.55,95 \% \quad \mathrm{CI}: 1.61-35.24) \quad$ were significantly associated with poor ART adherence(Table3). Also women with viral load
$>1000$ copies (OR=2,95\%CI: 0.32-13.352), were somewhat at risk to have poor ART adherence (Table 3).

\section{Experience of violence and ART adherence}

In bivariate analysis, Psychological and physical violence were associated with poor ART adherence but in multivariate analysis only psychological violence were observed to have association with GBV (OR=4.89, 95\%CI: 1.07 22.2) and were statistically significant (table 2.)

Table2. Factors associated with poor ART adherence among women attending care and treatment clinic at Mbeya Regional Referral Hospital, 2017

\begin{tabular}{|c|c|c|c|c|c|}
\hline \multirow[t]{2}{*}{ Characteristics } & \multirow{2}{*}{$\begin{array}{l}\begin{array}{l}\text { Poor ART } \\
\text { Adherence }\end{array} \\
\mathrm{N}(\%)\end{array}$} & \multicolumn{2}{|l|}{ Crude OR } & \multicolumn{2}{|l|}{ Adjusted OR } \\
\hline & & CI 95\% & p. value & $95 \% \mathrm{CI}$ & P. value \\
\hline \multicolumn{6}{|l|}{ Age } \\
\hline$<=35$ & $153(17.6)$ & 1 & & & \\
\hline$>35$ & $258(13.2)$ & $0.7(0.4-1.22)$ & 0.21 & $1.52(0.31-7.26)$ & 0.59 \\
\hline \multicolumn{6}{|l|}{ Education level } \\
\hline None /Primary & $292(15.4)$ & 1 & & & \\
\hline Secondary and above & $119(13.5)$ & $0.85(0.46-1.57)$ & 0.61 & $0.77(0.14-4.5)$ & 0.76 \\
\hline \multicolumn{6}{|l|}{ Occupation } \\
\hline $\begin{array}{l}\text { Employed in public } \\
\text { /private sector }\end{array}$ & $112(13.4)$ & 1 & & & \\
\hline self-employed & $299(15.4)$ & $1.12(0.62-2.2)$ & 0.61 & $1.89(0.33-10.6)$ & 0.46 \\
\hline \multicolumn{6}{|l|}{ Marital status } \\
\hline married & 184(11.4) & 1 & & & \\
\hline Not married & $227(17.6)$ & $1.66(0.64-2.93)$ & 0.07 & $1.14(0.25-5.05)$ & 0.85 \\
\hline \multicolumn{6}{|l|}{ Income } \\
\hline$>\mathrm{Tsh} .100,000 /=$ & $179(15.1)$ & 1 & & & \\
\hline$<=$ Tsh. $100,000 /=$ & $229(14.6)$ & $0.96(0.55-1.67)$ & 0.9 & $0.48(0.11-2.02)$ & 0.32 \\
\hline \multicolumn{6}{|l|}{ Disclosure } \\
\hline Yes & $331(11.8)$ & 1 & & & \\
\hline No & $80(27.5)$ & $2.84(1.56-5.14)$ & 0.001 & $1.12(0.21-5.81)$ & 0.88 \\
\hline \multicolumn{6}{|l|}{ History of alcohol use } \\
\hline No & $277(11.2)$ & 1 & & & \\
\hline Yes & $134(22.4)$ & $2.28(1.31-3.97)$ & 0.002 & $3.69(0.9-15.09)$ & 0.06 \\
\hline \multicolumn{6}{|l|}{ Life time partner } \\
\hline one & $340(13.5)$ & 1 & & & \\
\hline More than one & $71(21.1)$ & $1.71(0.89-3.27)$ & 0.1 & $0.49(0.05-4.16)$ & 0.51 \\
\hline \multicolumn{6}{|l|}{ Residence } \\
\hline Urban & $291(12.2)$ & 1 & & & \\
\hline Rural & $124(21)$ & $1.91(1.09-3.33)$ & 0.02 & $0.52(0.07-3.57)$ & 0.51 \\
\hline \multicolumn{6}{|l|}{ Distance from $\mathrm{H} / \mathrm{F}$} \\
\hline$<10 \mathrm{~km}$ & $252(10.7)$ & 1 & & & \\
\hline$>10 \mathrm{~km}$ & $70(21.4)$ & $2.26(1.3-3.93)$ & 0.003 & $5.65(0.75-42.03)$ & 0.09 \\
\hline \multicolumn{6}{|l|}{ Stigma } \\
\hline No & $297(11.5)$ & 1 & & & \\
\hline Yes & $112(23.7)$ & $2.4(1.37-4.2)$ & 0.001 & $7.55(1.61-35.24)$ & 0.01 \\
\hline \multicolumn{6}{|l|}{$\begin{array}{l}\text { Feeling difficult to } \\
\text { take medication }\end{array}$} \\
\hline No & $340(11.5)$ & 1 & & & \\
\hline Yes & $71(31)$ & $3.46(1.89-6.33)$ & 0.001 & $1.07(0.2-5.75)$ & 0.92 \\
\hline \multicolumn{6}{|l|}{$\begin{array}{l}\text { Satisfied with health } \\
\text { provider }\end{array}$} \\
\hline Yes & $219(13.2)$ & 1 & & & \\
\hline No & I92(16.7) & $1.31(0.76-2.25)$ & 0.33 & $1.29(0.34-4.77)$ & 0.07 \\
\hline
\end{tabular}


Gender-Based Violence and Adherence to Anti-Retroviral Therapy among Hiv-Infected Women Attending Care and Treatment Clinic, Mbeya Region 2017

\begin{tabular}{|c|c|c|c|c|c|}
\hline Resent viral load & & & & & \\
\hline$<1000$ & $84(19.1)$ & 1 & & & \\
\hline$>1000$ & 19(21.1) & $1.13(0.33-3.87)$ & 0.84 & $2(0.32-13.35)$ & 0.44 \\
\hline \multicolumn{6}{|l|}{ Family support } \\
\hline Yes & $126(11.9)$ & 1 & & & \\
\hline No & $285(16.1)$ & $0.76(0.37-2.66)$ & 0.26 & $0.43(0.08-2.27)$ & 0.32 \\
\hline $\begin{array}{l}\text { Physical violence } \\
\text { No } \\
\text { Yes }\end{array}$ & $\begin{array}{l}360(13.3) \\
51(25.5) \\
\end{array}$ & $\begin{array}{l}1 \\
2.22(1.1-47)\end{array}$ & 0.02 & $1.16(0.13-10.77)$ & 0.89 \\
\hline $\begin{array}{l}\text { Sexual violence } \\
\text { No } \\
\text { Yes }\end{array}$ & $\begin{array}{l}383(14.1) \\
28(25)\end{array}$ & $\begin{array}{l}1 \\
2.03(0.82-5)\end{array}$ & 0.11 & $0.11(0.08-9.24)$ & 0.88 \\
\hline $\begin{array}{l}\text { psychological } \\
\text { violence } \\
\text { No } \\
\text { Yes }\end{array}$ & $\begin{array}{l}329(10.3) \\
27(32.9)\end{array}$ & $\begin{array}{l}1 \\
5(2.38-7.61)\end{array}$ & 0.001 & $4.89(1.07-22.2)$ & 0.03 \\
\hline
\end{tabular}

\section{Violence}

Lifetime experience of any type of violence (psychological, physical or sexual) was reported by $102(24.8 \%)$ participants. The most common type of violence reported was psychological violence (19.9\%), followed by physical violence (12.4\%); sexual violence was the least frequently reported (6.8\%).59 participants had experienced more than one type of violence making a total of 102 who experienced any type of violence

\section{Characteristics Associated with Violence}

In univariate analysis, women who were currently not married were more likely to report violence than those who were not married $(\mathrm{OR}=1.78,95 \% \mathrm{CI}: 1.11-2.85)$ (table4), similarly to participants from rural areas $(\mathrm{OR}=2.17$, 95\% CI: 1.36-3.46), those who didn't disclose their HIV status (OR=1, 95\%CI:18-3.39), feeling difficult to take medication (OR=2, 95\%CI: 1.16-

Table3. Magnitude of violence (GBV) and associated factors in the studied population

\begin{tabular}{|l|l|l|l|l|l|}
\hline Characteristics & $\begin{array}{l}\text { Prevalence of any form } \\
\text { of violence N (\%) }\end{array}$ & $\begin{array}{l}\text { Crude OR } \\
\text { CI 95\% }\end{array}$ & p. value & $\begin{array}{l}\text { Adjusted OR } \\
\text { 95\% CI }\end{array}$ & $\begin{array}{l}\text { P. } \\
\text { value }\end{array}$ \\
\hline Age & & & & & \\
\hline$>35$ & $153(17.7)$ & 1 & & & \\
\hline$<=35$ & $258(13.1)$ & $0.7(0.4-2.22)$ & 0.22 & $0.85(0.24-2.98)$ & 0.8 \\
\hline Education level & & & & & \\
\hline $\begin{array}{l}\text { Secondary and } \\
\text { above }\end{array}$ & $112(20.5)$ & 1 & & & \\
\hline None /Primary & $299(26.4)$ & $0.9(0.55-1.49)$ & 0.69 & $1.1(0.29-4.05)$ & 0.88 \\
\hline Occupation & & & & & \\
\hline self-employed & $299(26.4)$ & 1 & & & \\
\hline $\begin{array}{l}\text { Employed in } \\
\text { public /private } \\
\text { sector }\end{array}$ & $112(20.5)$ & $1.38(0.82-2.35)$ & 0.2 & $1.64(0.44-.06)$ & 0.45 \\
\hline Marital status & & & & & \\
\hline married & $247(19)$ & & & & \\
\hline Not married & $227(29.5)$ & 1 & & & \\
\hline Income & & $1.78(1.11-2.85)$ & 0.01 & $0.79(0.24-.54)$ & 0.7 \\
\hline$>$ Tsh.100000/= & $179(21.8)$ & 1 & & & \\
\hline
\end{tabular}

3.46), Participants from $>10 \mathrm{~km}(\mathrm{OR}=1.67$, 95\% CI; 1-2.63), Life time partner ( $\mathrm{OR}=3.16$, 95\%CI:1.85-5.41), Self perceived stigma $(\mathrm{OR}=2.17,95 \% \mathrm{CI}: 1.35-3.49)$, and life time partner $(\mathrm{OR}=3.16,95 \% \mathrm{CI}: 1.85-5.41$. Ever having experienced violence was not significantly associated with alcohol use, education, age and house hold income.

\section{Multivariate Analysis}

Women who had history of alcohol use were significantly associated with experience of violence than those who didn't use alcohol $(\mathrm{OR}=5.18$, 95\%CI: 1.63-16.44), Also women who had more than one partner were three times more likely to report violence and statistically were significant (OR=3.16,95\%CI:1.85-5.41). While characteristics such as income, stigma, distance from health facility, family support were not associated with violence. 
Gender-Based Violence and Adherence to Anti-Retroviral Therapy among Hiv-Infected Women Attending Care and Treatment Clinic, Mbeya Region 2017

\begin{tabular}{|c|c|c|c|c|c|}
\hline$<=$ Tsh. $100000 /=$ & $232(27.2)$ & $1.33(0.84-2.11)$ & 0.21 & $2.27(0.89-.71)$ & 0.07 \\
\hline \multicolumn{6}{|l|}{ Alcohol use } \\
\hline No & $186(23.5)$ & 1 & & & \\
\hline Yes & $134(27.6)$ & $1.24(0.77-0.98)$ & 0.36 & $5.18(1.63-16.44)$ & 0.005 \\
\hline \multicolumn{6}{|l|}{ Disclosure } \\
\hline Yes & $331(22.1)$ & 1 & & & \\
\hline No & $80(36.3)$ & 2.(1.18-3.39) & 0.008 & $1.2(0.27-5.38)$ & 0.8 \\
\hline \multicolumn{6}{|l|}{$\begin{array}{l}\text { Distance from } \\
\mathrm{H} / \mathrm{F}\end{array}$} \\
\hline$<10 \mathrm{~km}$ & $282(21)$ & 1 & & & \\
\hline$>10 \mathrm{~km}$ & $159(30.8)$ & $1.67(1-2.63)$ & 0.02 & $0.26(0.04-.55)$ & 0.14 \\
\hline \multicolumn{6}{|l|}{$\begin{array}{l}\text { Feeling difficult } \\
\text { to take } \\
\text { medication }\end{array}$} \\
\hline No & $340(22.4)$ & 1 & & & \\
\hline Yes & $71(36.6)$ & $2(1.16-3.46)$ & 0.01 & $0.66(0.16-2.23)$ & 0.44 \\
\hline \multicolumn{6}{|l|}{ Life time partner } \\
\hline one & $340(20.6)$ & 1 & & & \\
\hline More than one & $71(45.1)$ & $3.16(1.85-5.41)$ & 0.001 & $8.01(1.62-39.42)$ & 0.01 \\
\hline \multicolumn{6}{|l|}{ Residence } \\
\hline Urban & $287(20.2)$ & 1 & & & \\
\hline Rural & $124(35.5)$ & $2.17(1.36-3.46)$ & 0.001 & $1.57(0.27-9.04)$ & 0.6 \\
\hline \multicolumn{6}{|l|}{$\begin{array}{l}\text { Satisfied with } \\
\text { health care }\end{array}$} \\
\hline Yes & 219(13.2) & 1 & & & \\
\hline No & 192(30.2) & $1.72(1.09-2.7)$ & 0.01 & $0.97(0.34-2.74)$ & 0.95 \\
\hline \multicolumn{6}{|l|}{ Family support } \\
\hline Yes & $75(20.6)$ & 1 & & & \\
\hline No & $336(26.7)$ & $1.26(0.69-2.32)$ & 0.26 & $1.31(0.39-4.35)$ & 0.43 \\
\hline \multicolumn{6}{|l|}{ Viral load } \\
\hline$<1000$ & $84(35.7)$ & 1 & & & \\
\hline$>=1000$ & $19(36.8)$ & $1.05(0.37-2.95)$ & 0.92 & $1.24(0.28-.41)$ & 0.76 \\
\hline \multicolumn{6}{|l|}{ Stigma } \\
\hline Yes & $298(20.5)$ & 1 & & & \\
\hline No & $114(35.9)$ & $2.17(1.35-3.49)$ & 0.001 & $0.48(0.28-.41)$ & 0.25 \\
\hline
\end{tabular}

\section{DISCUSSION}

The study intended to identify factors influencing adherence to ART treatment among women on ART, in this study the proportion of poor ART adherence among women attending care and treatment clinic were $14.8 \%$. Furthermore our study examined the association of violence and ART adherence to women on ART, and the prevalence of ever having violence were $(24.8 \%)$.

In the recent study factors like gender based violence, disclosure status, alcohol use, and perceived self stigma were independently association with the level of poor adherence than other factors. This finding is slightly different from study done in Tanzanian settings where age, education, level, and marriage were independently significantly associated with ART adherence(25)similar to study done in Ethiopia where factors like residence, educational status, substance use and occupation had significant association with the level of adherence (34).

Despite the adherence level is less than the recommended level; the obtained result was higher than other studies in different parts of Tanzania such as in Dares -salaam(29) while some studies shows adherence rate higher than our study(25).

Also the adherence rate in this study is lower than study done in Mbeya on adherence to highly Active Antiretroviral Therapy (HAART) among HIV/AIDS Adult Patients Attending CTC and the adherence level were (90-100\%)(35). In this study, we did not find an association between adherence to ART and socio-demographic characteristics. These findings similar to another study done on factors associated with nonadherent to antiretroviral therapy among HIV infected people in Pwani Region, eastern Tanzania(36). This is also similar to that seen in other areas, such in Lilongwe, Malawi (85.6\%) 
women said they adhere to ART (37). South west Ethiopia(36.19\%) had poor adherence and (63.8\%) had good adherence to their ART treatment(34), and other developing countries (adherence ranges from $40 \%$ to $70 \%$ )(38).

Fear of stigma may force PLWH/AIDS to hide their HIV status even to close members of the family. The result of this study showed that women who had perceived stigma had more likely to have poor ART adherent than none stigmatized and showed statistically significant association.

Further more psychological violence and physical violence were associated with level of ART adherence; therefore Violence can also cause a disorganized living environment, making women at increased risk of forgetting to take their ART medications properly(8).

The prevalence of exposure to violence in women that we observed was substantially lower than in previous reports from Tanzania Demographic Health Survey 2010 (15).

Furthermore, Shrivastava et al. found that $36.9 \%$ of women living in urban slums of Mumbai experienced psychological/verbal violence being the most common type (8), again comparable to our findings where physiological violence were the leading type in our study. In other countries, the prevalence of violence ranges from $37-55 \%$, in rural Uganda $36.6 \%$ of HIV infected women, reported experiencing intimate partner violence (39) which was more comparable to the our findings. Furthermore we were only able to demonstrate associations between violence and adherence and cannot determine whether one caused the other. More over we relied on selfreport to collect sensitive information on violence and ART adherence, thus creating potential for recall bias that may lead to overestimation of adherence level. Experience of violence is often considered a private family matter, there could be underreporting. In this study the sampling frame were drawn from appointment registers, clients who missed the CTC the day of interview might have gender violence, due to time constrain we didn't make follow up.

\section{CONClusion AND ReCOMMENDATION}

This study revealed that, the proportion of poor ART adherence and Gender based violence among women who attend care and treatment clinic is still high, also the study showed that, Gender based violence, residence, distance from health facility, undisclosed HIV status, having more than one partner, feeling difficult to take medication, self perceived stigma, alcohol use, were independently associated with poor adherence to ART. Reason for missing two or more than two ART doses were, being too busy, travelling and being sick. These problems also existed in other related researches conducted in Tanzania and other countries with the same factors even if their severity were different. Therefore,

Routine screening women for violence exposure may be useful in clinical settings where HIV services are provided to anticipate whether extra adherence support may be needed in order to increase adherence to ART, and Proper counseling of HIV/AIDS patient on importance of HIV status disclosure.

\section{ACKNOWLEDGMENTS}

Advice and supports from the faculties of Biostatistics and epidemiology, FELTP and CDC (Prof. G. Kwesigabo, Dr. J. Gibson, Dr. Candida Moshiro, and Dr. Harris) are gratefully acknowledged and deeply appreciated. Finally, participants who kindly agreed to participate in the thesis study and provided their valuable time for interviews are gratefully acknowledged.

\section{FUNDING}

We would like to thank Muhimbili University of Health and allied Science, FELTP program, CDC and Ministry of Health, community development, Gender, Elderly and Children (MoHCGEC) for funding this research

\section{AUTHORS' CONTRIBUTIONS}

ARL conceived and participated in designing, conducting, performing the statistical analysis and manuscript writing, GK and JG. Participated in designing and manuscript writing. All authors read and approved the final manuscript.

ETHICAL APPROVAL AND CONSENT TO PARTICIPATE

Ethical clearance was obtained from the ethical review committee of Muhimbili University of Health and allied Science. Written (or thumb impression if unable to write) consent was obtained from the participants.

\section{REFERENCES}

[1] USAID. Addressing gender issues related to HIV treatment adherence programs. US Agency Int Dev. 2010;1(August):1.

[2] IASC. Guidelines for Gender-based Violence Interventions in Humanitarian Settings. Response [Internet]. 2005;(September):383944. 3. 
[3] Tanzania Minitry of Health and Social Welfare (MOHSW). The National Policy Guideline for the Health Sector Prevention and Response tp Gender-Based Violence (GBV). 2011; (September).

[4] Ministry of Health and Social Welfare. The United republic of Tanzania Ministry of Health and Social welfare. National Aids Control Programme HIV/AIDS/STI Surveillance Report. 2013.

[5] National Aids Control Progrmme. The United Republic of Tanzania Ministry of Health and Social Welfare Tanzania Mainland National Guidelines for the Management of HIV and AIDS. www.nacp.go.tz. 2012. 133 p.

[6] Welfare TM of $\mathrm{H}$ and S. The United Republic of Tanzania Ministry of Health and Social Welfare, Natonal Guideline for complihensive Care Services for Prevention of Mother-toChildTransmission of HIV and Keeping Mothers alive. Guidline. 2013;53-6.

[7] Rodger A, Phillips A, Ph D. correspondence Prevention of HIV-1 Infection with Antiretroviral Therapy. N Engl J Med. 2011;1934-5.

[8] Nicodimos S. Association betweenDomestic violence and Adherence to Aniretroviral Therapy in Southern India. Public Heal Epidemiol. 2013;1(1):9.

[9] Schaecher KL. The Importance of Treatment Adherence in HIV. Am J Manag Care. 2013;19(12):231-7.

[10] USAID. Addressing gender in HIV adherence programs. Helth policy Initiat. 2006;1.

[11] Kouyoumdjian FG, Findlay N, Schwandt M, Calzavara LM. A Systematic Review of the Relationships between Intimate Partner Violence and HIV / AIDS. Dalla Lana Sch Public Heal. 2013;8(11):1-25.

[12] Linkindoki S. Addressing the links between gender-based violence and HIV in the Great Lakes region Tanzania. Ctry Rep. 2013;

[13] Hatcher A, Hatcher AM, Smout EM, Turan JM. Intimate partner violence and engagement in HIV care and treatment among women: a systematic review and meta-analysis. 2015; (August 2016).

[14] Bernstein M. Intimate partiner violence among HIV-infected pregnant women initiating antiretroviral therapy in South africa. Sch Public Heal Fam Med. 2015;

[15] Survey H, Findings K. Tanzania Demographic and Health Survey Key Findings. Tanzania Natl Bur Stat ICF Macro. 2010;

[16] National Bureau of Statistics Dar es Salaam T. Tanzania Demographic and Health Survey. Prelim Rep. 2010;
[17] Nyamhanga TM, Frumence G. Gender context of sexual violence and HIV sexual risk behaviors among married women in Iringa Region, Tanzania. Glob Health Action. 2014;7(1).

[18] Health, Welfare S. The United Republic of Tanzania Ministry ofHeath and Social Welfare, National Guidelines for the management of HIV. 2015;(April):154.

[19] Denison JA, Koole O, Tsui S, Menten J, Torpey $\mathrm{K}$, Mukadi YD, et al. Incomplete adherence among traetmen-experienced adults on antiretroviral therapy in Tanzania, Uganda and Zambia. 2016;29(3):361-71.

[20] Shaidi MV, Sciences A. Intimate partner violence among women living in informal settlements: A case study of manzese, in Dar es salaam, Tanzania. J Interpers violence. 2012;(November).

[21] Reda AA, Biadgilign S. AIDS Research and Treatment Volume 2012 (2012), Article ID 574656, 8 pages http://dx.doi.org/10.1155/2012 1574656 Review Article Determinants of Adherence to Antiretroviral Therapy among HIV-Infected Patients in Africa Ayalu A. Reda1 and Sibhatu Biadgilign. 2012;

[22] O'Malley TL. The intersection of intimate partner violence and HIV/AIDS among women in India: Moving beyond the individual. 2012;177.

[23] Nsimba SED, Irunde H, Comoro C. Barriers to ARV Adherence among HIV / AIDS Positive Persons taking Anti-Retroviral Therapy in Two Tanzanian Regions 8-12 Months after Program Initiation. J AIDS Clin Res. 2010;1(3):1-9.

[24] Sasaki Y, Kakimoto K, Dube C, Sikazwe I, Moyo C, Syakantu G, et al. Adherence to antiretroviral therapy (ART) during the early months of treatment in rural Zambia: influence of demographic characteristics and social surroundings of patients. Ann Clin Microbiol Antimicrob. 2012;11(1):34.

[25] Suzanne Maman2, Carol E. Golin2, Jo Anne Earp2 EE, Shrikant Bangdiwala3 and MJ 1Duke. Factors associated with self-reported adherence to antiretroviral therapy in a Tanzanian setting Melissa H. Watt1. 2013;22(3):381-9.

[26] Ebuy H, Yebyo H, Alemayehu M. Level of adherence and predictors of adherence to the Option B+ PMTCT programme in Tigray, northern Ethiopia. Int J Infect Dis. International Society for Infectious Diseases; 2015;33:e1239.

[27] Roy MP, Hospital S. Adherence to antiretroviral drugs. Indian J Med Res 143, Febr 2016. 2016;(February):245-6. 
[28] Hansana V, Sanchaisuriya P, Durham J, Sychareun V, Chaleunvong K, Boonyaleepun S, et al. Adherence to Antiretroviral Therapy (ART) among People Living With HIV (PLHIV): a cross-sectional survey to measure in Lao PDR. J Artic. 2013;1-11.

[29] Muya AN, Geldsetzer P, Hertzmark E, Ezeamama AE, Kawawa H, Hawkins C, et al. Predictors of Nonadherence to Antiretroviral Therapy among HIV-Infected Adults in Dar es Salaam, Tanzania. J Int Assoc Provid AIDS Care. 2015;14(2):163-71.

[30] Victoria NU, Sunday NO, Emmanuel IE, Brian O, Samuel UU, Matthew OJ. Assessment of highly active antiretroviral therapy (HAART) adherence among HIV patients in a tertiary health institution in Nigeria. African J Pharm Pharmacol. 2014;8(47):1192-9.

[31] Hampanda KM. Social Science \& Medicine Intimate partner violence and HIV-positive women â€TM s non-adherence to antiretroviral medication for the purpose of prevention of mother- to-child transmission in Lusaka, Zambia. Soc Sci Med. Elsevier Ltd; 2016;153:123-30.

[32] Shamu S, Zarowsky C, Shefer T, Temmerman M, Abrahams N. Intimate Partner Violence after Disclosure of HIV Test Results among Pregnant Women in Harare, Zimbabwe 2014. www.plosone.org. PLoS One. 9(10).
[33] Hardon A, Davey S, Gerrits T, Hodgkin C, Irunde $\mathrm{H}$, Investigator $\mathrm{P}$, et al. From access to adherence: the challenges of antiretroviral treatment Studies from Botswana, Tanzania and Uganda 2006. Eur Community. 2006;

[34] Abera A, Fenti B, Tesfaye T, Balcha F. Factors Influencing Adherence to Antiretroviral Therapy among People Living With HIV / AIDS at ART Clinic in Jimma University Teaching Journal of Pharmacological Reports. 2015;1(1) :1-6.

[35] A MMN. Adherence to Highly Active Antiretroviral Therapy (HAART) Among HIV/AIDS Adult Patients Attending Mbeya Referral Hospital, Tanzania. 2009;1:2.

[36] Idindili B, Jullu B, Mugusi F. A case-control study of factors associated with non-adherent to antiretroviral therapy among HIV infected people in Pwani Region, eastern Tanzania. 2012;14(3):1-12.

[37] Mbirimtengerenji ND, Jere G, Lengu S, Maluwa A. Factors That Influence Anti-Retroviral Therapy Adherence among Women in Lilongwe Urban Health. 2013;2013(March):16-25.

[38] Mitiku H, Abdosh T, Teklemariam Z. Factors Affecting Adherence to Antiretroviral Treatment in Harari National Regional State, Eastern Ethiopia. 2013;2013.

[39] Osinde MO, Kaye DK, Kakaire O. Intimate partner violence among women with HIV infection in rural Uganda: critical implications for policy and practice. 2011

Citation: Luoga, Alex Robert, J. Harris, J. Gibson, G. Kwesigabo, Gender-Based Violence and Adherence to Anti-Retroviral Therapy among Hiv-Infected Women Attending Care and Treatment Clinic, Mbeya Region 2017. ARC Journal of Public Health and Community Medicine.2019; 4(2):23-34. DOI: dx.doi. org/ 10.20431/24560596.0402004

Copyright: (C) 2019 Authors. This is an open-access article distributed under the terms of the Creative Commons Attribution License, which permits unrestricted use, distribution, and reproduction in any medium, provided the original author and source are credited. 